\title{
AOR
}

Selected Papers of \#AoIR2020:

The $21^{\text {st }}$ Annual Conference of the

Association of Internet Researchers

Virtual Event / 27-31 October 2020

\section{ECHOLOCATING THE DIGITAL SELF: A CONCEPTUAL FRAMEWORK}

Annette N. Markham

RMIT University

\section{Introduction/Overview}

Bats send out a continuous series of shrieks as they fly, using the returning echoes to build up a sonic map of their surroundings. navigate through space. The speed and sound of the responding echo tells them the location and shape of material around them. How is this related to internet studies?

Echo-location, in the way we might think of radar, sonar, or lidar, serves as an useful metaphor for describing the process of searching for and locating the Self in an era of constant connectivity and 'always on' (Turkle, 2008) --or more importantly, 'always available' internet.

Building from foundational symbolic interactionist theories that the Self is social (Mead, 1934), performative (Goffman, 1959), and relational (from Cooley's notion of the looking glass self (1902) to Gergen's notions of the populated self in 1991), this work focuses on the quality of the response in micro moments of the symbolic interaction process. It argues that these are central in positioning or mapping social space as well as the characteristics of the Self within these spaces, particularly in, but not limited to, digitally saturated contexts.

The discursive and material responses of digital interfaces --red dots, numbers, hearts, checkmarks - often colloquially called 'pings,' play key and active roles in digital interactions. Pings can be conceptualized as having qualities of liveness: They are primary (rather than mediating) interlocutors, interpersonal partners in ongoing interactions through which the individual constructs self identity. 
This conceptual frame of echolocation contributes to stronger theorizing about a) what is happening in and through the continuous 'call and response' of pings, notifications, information exchange, and b) why it is so difficult to disconnect from social media.

\section{Methodology}

The development of the theory of social echolocation draws on my observations and close readings of autoethnographic accounts of a group of around 50 young participants, a theoretical sample from a larger 6-year study (involving approximately 1500 persons, between 2012-2018, about everyday social media use (cf Markham, 2018; Tiidenberg, et al, 2017). Participants were selected because they mention the importance of responses or indicate distress about being disconnected. Participants generated material through guided autoethnographic study of their own digital lived experience, including periods of deliberate disconnection from various digital media. Material analyzed includes video, audio, and written narratives.

Participants granted informed consent. Sensitive material is stored according to GDPR regulations and anonymized appropriately, following best practices AoIR guidelines. Material presented effectively obscures personally identifiable information.

\section{Reliance and anxiety regarding notifications}

In some ways, the participants' perceptions of notifications are not surprising. Some types of notifications are useful, such as double checkmarks in messaging apps ("I immediately see whether my friends have seen my question, and for some reason, I feel better, like people are there." says Marie, Danish, age 26).

Other types of notifications, especially push notifications like red dots on iPhone screens or audible pings are annoying, interruptive. As Paolo, a 24-year-old Italian remarks, "I hate seeing those evil red dots! They bug me until I finally check them, to make them disappear." Not only are they stressful (cf., Kushlev, Proulx, \& Dunn, 2016; Pielot \& Rello, 2017), they produce pressure to check one's device repeatedly (as 22year-old Jax from USA says, "I'm so mad at myself for not being able to wait until the end of class to check. Why am I so obsessed with instant responses?'). This tendency has been linked to increased dopamine production, suggesting notifications are addiction (Haynes, 2018). Whether or not addictive, the experience of notification is powerful. As Paul Frosh remarks, "The wrongly colored ticks are a wound, cutting into me as a blade. ...It bruises me, it immobilizes me, it reveals the termination of connection" (2017, np).

Participants express deep anxiety especially when they receive too few or no responses. The unexpected absence of response might indicate that they can no longer verify the presence or status of others, but more interesting to the present study, it's associated with feelings of deep vulnerability about the presence and status of the Self. In a way, participants feel as if they themselves have disappeared.

\section{Disconnection as Ontological Dysphoria}


Their expressions of vulnerability take us in a different direction about identity formation in the digital age. Previous conceptual work has tended to focus on how digital identity is a matter of performativity (e.g., Sunden's 2003 notion that we write ourselves into being); that it occurs through multiple windows (Turkle, 1995) or on multiple front- and back-stages (e.g., Pearson, 2008, drawing on Goffman, 1959). My ethnographic work suggests that digital identity is even more deeply linked to the quality and characteristics of the responses to these performances than we have previously theorized in studies of digital identity. At the granular level of the interaction through which self is relationally constructed and reified, we can ask what is happening in and just following the moment of the ping, checkmark, push notification, or other form of informational echoes? These moments are when and how the Self makes sense of what they signaled (cf. Donath 2007) and not only respond in kind, but simultaneously build self awareness through micro adjustments, as Weick discussed in his early work on the social psychology of sensemaking (1969).

This connects to recent explorations on distraction and affective modulation by Susanna Paasonen (2016) or the phenomenology of "operative attention" by Paul Frosh (2019). These affect scholars are among those who attend to these granular levels where we can see micro shifts in affect. Sharif Mowlabocus (2016), for example, focuses on the rhythms of what occurs in what he calls "interstitial time," or "moments when we become uncertain - about what to do next, about how to occupy our time, about how to 'be' in a particular space, perhaps even about our life trajectories" (np). Echolocation contributes to this discussion by focusing on how certainty is a matter of continuous call, response, and adjustment. In the case of bats, the outcome is flying at high speeds, avoiding obstacles, and catching small insects. In digital culture, it enables people to assess their position relative to others in multiple networks and relations.

Even more, the presence of a continuous 'call and response' ontological positioning becomes visible when it is absent. Disconnecting results in being removed from the continual process of marking the social state of Self and Other. When the self is identified through the flow of responses, and suddenly there is no response, it can cast the social body into doubt. As Celia, a 25-year-old Bulgarian writes, "I was only disconnected for two hours, but it was not pleasant. It was like I didn't know where I was or what I should do." This is not like removing one of the senses. Rather, the body suddenly appears as a discrete, separate, and isolated object. This ontological dysphoria is poignantly expressed by participants like Sara, a 24-year-old German: "I know I'm right here and it's ridiculous to feel so dependent on my phone. But turning off all my apps even for a few hours has made me feel like I'm not anywhere."

This paper is part of a larger project to build a symbolic interactionist conceptual frame that gives attention to the qualities and functions of human and nonhuman responses, not just as feedback or social validation, but as echoes through which we locate and demarcate boundaries of our selves.

\section{References}

Cooley, C. H. (1902). Human Nature and the Social Order. C. Scribner's Sons. 
Donath, J. (2007). Signals in social supernets. Journal of Computer Mediated Communication, 13(1). 231-251. https://doi.org/10.1111/j.1083-6101.2007.00394.x

Frosh, P. (2019). The Poetics of Digital Media. Polity Press.

Frosh, P. (2017). Vital Signs: Screenshots, Social Media and Existential Delegation. Precarious Media Life Conference. Sigtuna, Sweden, October 30.

Gergen, K. (1991). The Saturated Self. Basic Books.

Goffman, E. (1959). The Presentation of Self in Everyday Life. Doubleday Publishers.

Haynes, T. (2018). Dopamine, smartphones, and you: A battle for attention. Harvard University Science in the News Blog, Available from:

http://sitn.hms.harvard.edu/flash/2018/dopamine-smartphones-battle-time/

Mead, G. H. (1967/1934). Mind, Self and Society from the Standpoint of a Social Behaviorist. University of Chicago Press.

Kushlev, K., Proulx, J., and Dunn, E. W. (2016). "Silence Your Phones": Smartphone notifications increase inattention and hyperactivity symptoms. In Proceedings of the 2016 CHI Conference on Human Factors in Computing Systems. New York. DOI: http://dx.doi.org/10.1145/2858036.2858359

Markham, A. N. (2018). Critical pedagogy as a response to datafication. Qualitative Inquiry, Online First edition at https://doi.org/10.1177/1077800418809470

Markham, A. N. (2013). Dramaturgy of digital experience. in Edgley, C. (Ed.). The Drama of Social Life (pp. 279-294). Ashgate Press.

Mowlabocus, S. (2016). The 'mastery' of the swipe: Smartphones, transitional objects and interstitial time. First Monday, 21(10). https://doi.org/10.5210/fm.v21i10.6950

Paasonen, S. (2016). Fickle focus: Distraction, affect and the production of value in social media. First Monday, 21(10). https://doi.org/10.5210/fm.v21i10.6949

Pearson, E. (2009). All the World Wide Web's a stage: The performance of identity in online social networks. First Monday, 14(3).

Pielot, M. \& Rello, L. (2017). Productive, Anxious, Lonely: 24 Hours Without Push Notifications. In Proceedings of the MobileHCI Conference. Vienna, Austria.

Sunden, J. (2003). Material Virtualities: Approaching Online Textual Embodiment. Peter Lang.

Tiidenberg, K., Markham, A.N., Pereira, G., Rehder, M., Sommer, J., Dremljuga, R., \& Dougherty, M. (2017). "I'm an addict" and other sensemaking devices: A discourse 
analysis of self-reflections of lived experience on social media. Proceedings of the 8th International Conference on Social Media \& Society. Article No. 21. Available:

http://dl.acm.org/citation.cfm?doid=3097286.3097307

Turkle, S. (2008). Always-on/Always-on-you: The tethered self. In Katz, J. (Ed.). Handbook of Mobile Communication Studies (121-138). MIT Press.

Turkle, S. (1995) Life on the Screen. Simon \& Schuster.

Weick, K. (1969). Social Psychology of Organizing. Addison-Wesley. 